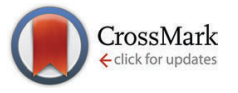

Cite this: Phys. Chem. Chem. Phys., 2016, 18, 31338

DOI: $10.1039 / \mathrm{c} 6 \mathrm{cp} 90272 \mathrm{c}$

www.rsc.org/pccp

\section{Correction: Achieving high resolution and optimizing sensitivity in spatial frequency encoding NMR spectroscopy: from theory to practice}

\author{
Bertrand Plainchont, Daisy Pitoux, Ghanem Hamdoun, Jean-Michel Ouvrard, \\ Denis Merlet, Jonathan Farjon and Nicolas Giraud*
}

Correction for 'Achieving high resolution and optimizing sensitivity in spatial frequency encoding NMR spectroscopy: from theory to practice' by Bertrand Plainchont et al., Phys. Chem. Chem. Phys., 2016, 18, 22827-22839.

The authors would like to correct an error in the published results: the E-Snob pulse whose amplitude profile is presented in Fig. 8 in the main text, and Fig. S4 in ESI, was calibrated for $90^{\circ}$ (instead of $270^{\circ}$ ).

The authors note that this calibration to $90^{\circ}$ does not correspond to the optimal setting for an E-Snob shape. E-Snob pulses calibrated for $270^{\circ}$ are actually as suitable as E-Burp2 and Gaussian pulses for performing a Spatial Frequency Encoding excitation step (see for instance eMagRes, 2016, 5, 1377-1382, DOI: 10.1002/9780470034590.emrstm1528). The authors apologize for this error.

The Royal Society of Chemistry apologises for these errors and any consequent inconvenience to authors and readers. 